\title{
Study of Lipid Profile in Acute Myocardial Infarction within 24 Hours
}

\author{
Prashant Kumar ${ }^{1}$, Siddharth Singh ${ }^{2 *}$, Suresh Prasad ${ }^{1}$, Umesh Prasad Yadav ${ }^{3}$ and Pramod Kumar Agrawal ${ }^{1}$ \\ ${ }^{1}$ Department of General Medicine Katihar Medical College, Katihar, Bihar, India \\ ${ }^{2}$ Department of General Medicine AIIMS Patna, Bihar, India \\ ${ }^{3}$ Department of Biochemistry, All India Institute of Medical Sciences, Patna, Bihar, India
}

\begin{abstract}
Background: Increased level of total cholesterol and LDL-cholesterol disturbs the endothelial function that may cause various cardio vascular disease and coronary heart disease. In addition, it can be expected, that hypercholesterolemia may unfavourably influence the course of the acute myocardial infarction. The aim of the study was to check whether patients with lipid levels above normal first 24 hours of myocardial infarction have an unfavorable clinical outcome.

Methods: Study was designed on 60 patients (46-men and14-women) of different age groups admitted with myocardial infarction within first 24 hours of onset of symptoms. 20 normal healthy individuals with normal ECG and no family history of coronary heart disease were selected as control. The clinical history and physical examination confirmed the AMI by the cardiac specific enzyme Creatine Kinase (CK) and Creatine Kinase myocardial b fraction (CK-MB), Troponin (T) and ECG. Blood samples were taken within 24 hours of acute myocardial infarction. Serum concentration of TC, TG, HDL-C were estimated by semi auto analyser. Analysis of variance (ANOVA) followed by Tukey's post hoc test was done to evaluate the association between the mean values of serum samples and clinical outcome. A probability value $p<0.05$ was considered statistically significant.

Result: In the control group, the means of TC, TG, HDL-C, LDL-C and VLDL-C were found to be $172.2 \mathrm{mg} / \mathrm{dl}, 147.6 \mathrm{mg} / \mathrm{dl}, 45.52,97.16 \mathrm{mg} /$ $\mathrm{dl}$ and $29.52 \mathrm{mg} / \mathrm{dl}$ respectively. In the present case study, the mean TC was $208.53 \mathrm{mg} / \mathrm{dl}$, mean TG was 168.73 , mean HDL-C was 41.65 mg/dl, mean LDL-C was $133.13 \mathrm{mg} / \mathrm{dl}$ and mean VLDL-C was $33.74 \mathrm{mg} / \mathrm{dl}$.

Conclusion: We found that the occurrence of disease is more in male patient than the female and the male/female ratio was 3.28:1. The patients above the age of 60 years were more prone to develop myocardial infarction and the major risk factors were smoking, hypertension and diabetes. It has also been observed that most of the patients had high level of LDL-cholesterol and low level of HDL-cholesterol within 24 hours onset of myocardial infarction.
\end{abstract}

Keywords: Acute Myocardial Infarction (AMI), Myocardium, Cardiac Specific Enzyme, Lipoproteins.

\section{Introduction}

Ischemic heart disease (IHD) or Coronary Artery disease $(C A D)$ is a condition in which there is an inadequate supply of blood and oxygen to a portion of the myocardium; it typically occurs when there is an imbalance between myocardial oxygen supply and demand. The most common cause of myocardial ischemia is atherosclerotic disease of an epicardial coronary artery (or arteries) sufficient to cause a regional reduction in myocardial blood flow and inadequate perfusion of the myocardium supplied by the involved coronary artery. For many years, it has been proclaimed that coronary heart disease (CHD) was not applicable to traditional risk factors in up to $50 \%$ of cases and was finally concealed after careful and detailed re-analysis (1). Dyslipidemia is still a major risk factor for CHD. Epidemiological studies have conclusively linked high levels of total cholesterol (TC) and low-density lipoprotein cholesterol (LDL-C) and low levels of high density lipoprotein cholesterol (HDL-C) with CHD incidence and mortality (2). It is well known that early treatment of hyperlipidemia followed by acute myocardial infarction (AMI) provides potential benefits to reduce the morbidity and mortality of CHD. However, lipid and lipoproteins level gets changed during acute illnesses that results delay in treatment choice (3). In post-acute coronary events, acute phasic changes occur that alter the lipid profile levels during tissue necrosis. Modifications of serum lipids after $A M I$ induce the reduction in TC, LDL and $\mathrm{HDL}$, in the range of $10-20 \%$, with the reciprocal increase in triglyceride (TG) of approximately 20 - 30 \% (1). Several mechanisms accounts for these changes which include the acute phase response associated with up-regulation of LDL-receptor (R) activity and reduction in several pivotal HDL regulatory proteins. From many clinical studies it is clear that phasic changes do occur in patients undergone $\mathrm{AMl}$ and therefore it is recommended for 
detection of hyperlipidemia in patients with AMI so that the serum lipids should be assessed either within 24 hours after infarction or after 2-3 months of AMI (4). Accurate knowledge of baseline lipid levels may affect the initiation of lipid lowering therapy, the selection of a specific statin and its dosage, and recognition of the potential need for adjunctive lipid therapy, and it may also influence the patient's willingness to adhere to a recommendation for longterm lipid-lowering therapy (5). Besides alterations in the lipoproteins, acute-phase response is also associated with changes in serum concentration of inflammatory markers. The patients with major adverse cardiac events shows intra-cardiac inflammatory response in AMI that appears as a result of the evolution of myocardial necrosis, shown by higher C-reactive protein (CRP) and interleukin (IL)6 levels in those patients (6). IL-6 is a multifunctional cytokine regulating humoral and cellular responses which plays central role in inflammation and tissue injury. Similarly to CRP, whose synthesis is stimulated by IL- 6 , high circulating concentrations of IL- 6 are associated with increased risk of cardiovascular events (7).

Several population based prospective studies of CHD have reported a close association of subtle, prolonged increases in baseline high sensitive hsCRP levels with cardiovascular risk (8). The majority of authors concur in that the admission hs-CRP concentration reflects the baseline inflammatory status of the patient; thus, patients with AMI and high hs-CRP levels at admission usually experience more cardiovascular complications during follow-up $(9,10)$ stated that increase in concentration of low density lipoprotein (LDL) cholesterol or decrease in level of high density lipoprotein (HDL) cholesterol are important risk factors for coronary atherosclerosis. In addition to these risk factors, high level of total cholesterol and LDL-cholesterol also disturbs the endothelial function (11). Thus it can be expected, that hypercholesterolemia may influence the course of the acute myocardial infarction in an unfavorable manner. An another study investigated the lipid profile in cardiac patients (myocardial infarction, angina pectoris, coronary heart disease, ischemic heart disease), diabetic patients and normal humans (12). Higher level of total cholesterol, LDL-C and triglyceride were found in both cardiac and diabetic patients, however, cardiac patients had much lower level of HDL-C as compared to normal humans. Dietary and exercise strategies can lead to modest and variable improvements in $\mathrm{HDL}-\mathrm{C}$ concentrations and other vascular risk factors also which may be associated with greater anti-oxidative potential of HDL (13).

The best-known function of HDL is its antiatherogenic ability for promoting the efflux of cholesterol from cells.

Temelkov, 2009 et al (14) reported that patients with hypercholesterolemia, hypertriglyceridemia and low HDL-c are more prone towards macro vascular disease, which automatically leads to stroke and myocardial infraction. The aim of this study was to prospectively evaluate the magnitude of the variations in lipid levels in a large population of patients admitted for acute myocardial infarction (MI) 24 hours of onset of symptoms. Clinical data and blood samples were prospectively collected from consecutive patients with MI.

\section{Materials and Methods}

The present work has been carried out in 60 cases (male: 46 and female: 14), attending in emergency of Katihar Medical College and Hospital and 20 normal healthy persons with normal ECG and no family history of coronary heart disease were selected as control. We included patients if they met all the following criteria: (a) all patients had AMI at baseline; (b) blood sample for lipid profile and inflammatory markers estimation was obtained within $24 \mathrm{~h}$ from the onset of symptoms. Informed consent were taken from the cases and controls before enrolment in the study. Men and women of different age groups are admitted with first myocardial infarction within first 24 hours of onset of symptoms (Table 1). The presence of different risk factors in cases are also enlisted (Table 2). Diagnosis of acute myocardial infarction was based on the pressure of any two of the following classical findings. Clinical history and physical examination data, focusing on characteristics of chest pain lasting more than 30 minutes and presence of cardiovascular risk factors were recorded for every patient. Rise and fall of cardiac specific enzymeCK and CKMB (elevation to at least twice the upper limit of normal range) or Troponin ' $T$ ' positivity by kit method [Roche CARDIAC Trop T Sensitive test (visual)]. Patients admitted with AMI, but having one or more of the findings were excluded from the study i.e. having definite history of ECG evidence of prior Ml, patients presenting more than 24 hours of onset of symptoms, chronic renal failure/renal 
parenchymal disease, nephritic syndrome, liver disease, disabling terminal illness.

Blood samples were taken within 24 hours of acute myocardial infarction. Serum concentration of TC, TG, HDL-C were estimated by semi auto analyzer (Transasia Bio-Medicals Ltd.). For TG; $1 \mathrm{ml}$ blood was centrifuged. Then $10 \mathrm{ml}$ serum mixed with reagent. For TC; $10 \mathrm{ml}$ serum was taken after centrifugation and mixed with $1 \mathrm{ml}$ cholesterol reagent. For HDL-C estimation; $0.2 \mathrm{ml}$ serum was mixed with HDL reagent $0.2 \mathrm{ml}$ to precipitate serum which was centrifuged at $2000 \mathrm{rpm}$ for 10 minutes, $20 \mathrm{ml}$ supernatant was again mixed with $1 \mathrm{ml} \mathrm{HDL}$ reagent. The entire reagent was incubated at $37^{\circ} \mathrm{C}$ and took its reading. Serum $\mathrm{Na}^{+} / \mathrm{K}^{+}$, B. Urea, S. Creatinine were estimated to rule out electrolyte imbalance and renal failure. Troponin (T) was tested only qualitative by kit method as mentioned earlier. Appearance of 2 lines was taken as positive while single line was taken as a valid but negative test. Hb\%, TLC, DLC, ESR were routinely measured in each and every patient. Blood sugar fasting and post prandial was done to know the glycaemic status of the patient. Serum bilirubin, SGPT, Serum albumin \& globulin were done to exclude significant liver derangement. Independent sample t-tests were used to compare the mean values of variables between the AMI and control groups, whereas chi-square test was used for association between two categorical variables. To evaluate the association between serum samples the mean values were compared by one way analysis of variance (ANOVA) followed by Tukey's post hoc test. A probability value $p<0.05$ was considered statistically significant.

\section{Results}

The serum lipid profile of total cholesterol (TC), total triglyceride (TG), high density lipoproteincholesterol (HDL-C), low density lipoproteincholesterol (LDL-C) and very low density lipoprotein- cholesterol (VLDL-C) were estimated and their association, as well as causation in myocardial infarction was determined. The levels of total cholesterol, HDL-C, triglyceride and LDL-C in cases and controls are shows in table 3 . In the control group, the mean TC was $172.2 \mathrm{mg} / \mathrm{dl}$, mean TG was $147.6 \mathrm{mg} / \mathrm{dl}$, mean HDL-C was 45.52, mean LDL-C was $97.16 \mathrm{mg} / \mathrm{dl}$ and mean VLDL-C was $29.52 \mathrm{mg} / \mathrm{dl}$. In the control group, the mean total cholesterol in men was $177.4 \mathrm{mg} / \mathrm{dl}$ and in women was $156.6 \mathrm{mg} /$ dl. The mean HDL-C in men was $44.34 \mathrm{mg} / \mathrm{dl}$ and in women was $49.04 \mathrm{mg} / \mathrm{dl}$. According to these reading the TC/HDL-C ratio in men was 4.08 whereas only 3.202 in women showing a better profile in women. Lipid profile among cases and control with $\mathrm{AMI}$ are listed in table 4 . In addition TC/HDL-C ratio of two sexes in control and patients with $\mathrm{AMl}$ are given in table 5. However, the details analytical values of given parameters are provided in table 6. The analysis showed that the highest number of cases was found in the age of $61-70$ years i.e. $36.6 \%$. Incidence of acute myocardial infarction in the young age group (30-40 years) was $10 \%$ and this is also significant. Acute myocardial infarction patients showed a male preponderance. The male to female ratio was 3.28:1. Hypertension was present in $40 \%$ cases, smoking habit was present in $36.6 \%$ and $16.6 \%$ of cases were diabetic. A family history of coronary artery disease was present in $26.6 \%$ of cases. Serum Total Cholesterol (TC), Total Triglyceride (TG), HDLCholesterol, LDL-Cholesterol and VLDL-cholesterol were estimated in all 60 patients and 20 control subjects. In addition, the mean total cholesterol in control group was $177.4 \mathrm{mg} / \mathrm{dl}$ and $156.6 \mathrm{mg} / \mathrm{dl}$ in men and women respectively. Similarly, the mean $\mathrm{HDL}-\mathrm{C}$ in men and in women was $44.34 \mathrm{mg} / \mathrm{dl}$ and $49.04 \mathrm{mg} / \mathrm{dl}$ respectively. The TC/HDL-C ratio in men was 4.08 whereas only 3.202 in women showing a better profile. Depression of HDL-Cholesterol in cases as compared to control subjects was also significant.

Table 1: Incidence of acute myocardial infarction in different age groups.

\begin{tabular}{|c|c|}
\hline Age groups (years) & No. of cases \\
\hline $30-40$ & 6 \\
\hline $41-50$ & 17 \\
\hline $51-60$ & 14 \\
\hline $61-70$ & 20 \\
\hline $71-80$ & 3 \\
\hline Total & 60 \\
\hline
\end{tabular}


Table 2: Showing the presence of different risk factors in cases.

\begin{tabular}{|c|c|c|}
\hline SI. No. & Risk factors & No. of cases \\
\hline 1. & Diabetes Mellitus & 10 \\
\hline 2. & Hypertension & 25 \\
\hline 3. & Family history of coronary artery Disease & 16 \\
\hline 4. & Family history of dyslipidemia & 5 \\
\hline 5. & Smoking & 22 \\
\hline
\end{tabular}

Table 3: The levels of Total cholesterol, HDL-C, Triglyceride and LDL-C in cases and controls.

\begin{tabular}{|c|c|c|c|}
\hline Finding & Levels & Case & Control \\
\hline \multirow[t]{6}{*}{ Total cholesterol } & \multirow[t]{2}{*}{$<200 \mathrm{mg} / \mathrm{dl}$} & $20(43.5 \%)$ & $14(93.3 \%)$ \\
\hline & & $6(42.8 \%)$ & $4(80 \%)$ \\
\hline & \multirow[t]{2}{*}{$200-239 \mathrm{mg} / \mathrm{dl}$} & 17 (36.9\%) & $1(6.6 \%)$ \\
\hline & & $8(57.2 \%)$ & $1(20 \%)$ \\
\hline & \multirow[t]{2}{*}{$\geq 240 \mathrm{mg} / \mathrm{dl}$} & $9(19.6 \%)$ & Nil \\
\hline & & Nil & Nil \\
\hline \multirow[t]{3}{*}{ HDL-C } & $<35 \mathrm{mg} / \mathrm{dl}$ & $13(21.7 \%)$ & Nil \\
\hline & $35-60 \mathrm{mg} / \mathrm{dl}$ & $47(78.3 \%)$ & $20(100 \%)$ \\
\hline & $>60 \mathrm{mg} / \mathrm{dl}$ & Nil & Nil \\
\hline \multirow[t]{2}{*}{ Triglyceride } & $<150 \mathrm{mg} / \mathrm{dl}$ & $29(48.3 \%)$ & $8(40 \%)$ \\
\hline & $>150 \mathrm{mg} / \mathrm{dl}$ & $31(51.7 \%)$ & $12(60 \%)$ \\
\hline \multirow[t]{3}{*}{ LDL-C } & $<100$ & $5(8.3 \%)$ & $10(50 \%)$ \\
\hline & $100-129$ & $20(33.3 \%)$ & $9(45 \%)$ \\
\hline & $>130$ & 35 (58.4\%) & $1(5 \%)$ \\
\hline
\end{tabular}

Table 4: Lipid profile among cases and control with AMI.

\begin{tabular}{|c|c|c|c|c|}
\hline \multirow{2}{*}{ Serum Lipids } & \multicolumn{2}{|r|}{ Case } & \multicolumn{2}{|r|}{ Control } \\
\hline & Mean (mg/dl) & $\begin{array}{l}\text { (Standard deviation } \\
( \pm \text { S.D. } \mathrm{mg} / \mathrm{dl})\end{array}$ & Mean (mg/dl) & (Standard deviation (+S.D. mg/dl) \\
\hline $\mathrm{TC}$ & 208.53 & 24.709 & 172.2 & 16.618 \\
\hline TG & 168.73 & 50.769 & 147.6 & 24.724 \\
\hline HDL-C & 41.65 & 6.617 & 45.52 & 6.441 \\
\hline VLDL-C & 33.74 & 10.153 & 29.52 & 4.944 \\
\hline LDL-C & 133.13 & 19.74 & 97.16 & 15.891 \\
\hline TC/HDL-C ratio & 5.154 & 0.946 & 3.86 & 0.717 \\
\hline
\end{tabular}

Table 5: TC/HDL-C ratio of two sexes in control and patients with AMI.

\begin{tabular}{|c|c|c|c|c|c|c|c|c|}
\hline \multirow[t]{2}{*}{ Sex } & \multicolumn{4}{|c|}{ Case } & \multicolumn{4}{|c|}{ Control } \\
\hline & No. & Mean TC mg/dl & $\begin{array}{l}\text { Mean } \\
\text { HDL-C }\end{array}$ & $\begin{array}{c}\text { TCl } \\
\text { HDL-C } \\
\text { ratio }\end{array}$ & No. & $\begin{array}{c}\text { Mean TC mg/ } \\
\text { dl }\end{array}$ & $\begin{array}{l}\text { Mean } \\
\text { HDL-C }\end{array}$ & $\begin{array}{c}\text { TCl } \\
\text { HDL-C } \\
\text { ratio }\end{array}$ \\
\hline Male & 46 & 214.43 & 40.54 & 5.447 & 15 & 177.4 & 44.34 & 4.08 \\
\hline Female & 14 & 189.14 & 45.31 & 4.19 & 5 & 156.6 & 49.04 & 3.202 \\
\hline
\end{tabular}


Table 6: The significance of clinical characteristics of patients and controls.

\begin{tabular}{|c|c|c|c|c|c|c|}
\hline Finding & & Range & Mean & (Value Mean) $^{2}$ & Z value & $p$-value \\
\hline \multirow[t]{2}{*}{$\mathrm{TC}$} & Case & $160-252$ & 208.53 & 36633.92 & \multirow[t]{2}{*}{7.42} & \multirow[t]{2}{*}{$<0.001$} \\
\hline & Control & $146-207$ & 172.2 & 5247.2 & & \\
\hline \multirow[t]{2}{*}{ TG } & Case & $106-408$ & 168.73 & 154651.96 & \multirow[t]{2}{*}{2.46} & \multirow[t]{2}{*}{$<0.01$} \\
\hline & Control & $96-199$ & 147.6 & 11614.8 & & \\
\hline \multirow[t]{2}{*}{ LDL } & Case & $84-175.8$ & 133.13 & 23380.4 & \multirow[t]{2}{*}{8.23} & \multirow[t]{2}{*}{$<0.001$} \\
\hline & Control & $72-136$ & 97.16 & 4798.36 & & \\
\hline \multirow[t]{2}{*}{ HDL } & Case & $29.2-50.8$ & 41.65 & 2627.52 & \multirow[t]{2}{*}{2.31} & \multirow[t]{2}{*}{$<0.01$} \\
\hline & Control & $31.4-55$ & 45.52 & 788.426 & & \\
\hline \multirow[t]{2}{*}{ VLDL } & Case & $21.2-81.6$ & 33.74 & 6185.85 & \multirow[t]{2}{*}{2.46} & \multirow[t]{2}{*}{$<0.01$} \\
\hline & Control & $19.2-39.8$ & 29.52 & 464.52 & & \\
\hline \multirow[t]{2}{*}{ TC/HDL } & Case & $3.715-7.606$ & 5.154 & 53.696 & \multirow[t]{2}{*}{6.45} & \multirow[t]{2}{*}{$<0.001$} \\
\hline & Control & $2.78-5.54$ & 3.86 & 9.7695 & & \\
\hline
\end{tabular}

\section{Discussion}

A series of changes in lipid metabolism occur during acute phase response. In the present study majority of the patients are in old age groups (i.e. 61-70 years). In a study by American Heart Association reported that approximately $4 / 5^{\text {th }}$ of myocardial infarction occurred in individuals aged 65 years and above. It was further also supported by various other studies previously done by Volmink 1998 et al (15) and Pedoe 1999 et al (16) that showed that most of the myocardial infarction occurred above 60 years and 70 years of age. In the present study out of total 60 patients the number of male patients are higher than the female $(M=46$ and $F=14)$. The male/female ratio was 3.28:1. Our study was again supported by Lerrier, DJ and Kannel WB (17) who observed $60 \%$ of coronary events occurred in men. Furthermore, Lampe 2000 et al (18) and Tunstall-Pedoe 1999 et al (16) reached to the finding that for every 4.1 males only 1 female suffered myocardial infarction and $75 \%$ of the sufferers of myocardial infarction were males respectively. So, the study showed male preponderance in acute myocardial infarction. In the present study history of smoking was found in 22 patients (36.6\%). Literatures are available in support of smoking as risk factors of hypertension which was predictors of cardiovascular risk Nina 2007 et at and Jan Borgel 2006 et al in $(19,20)$. Hypertension was related to the incidence of myocardial infarction, in current study, 24 patients (40\%) are found to be hypertensive; it was supporting the study done by Sajuelsson et al (1990) previously. It was further also supported by Bartel 2007 et al (21), who observed similar relationship between hypertension and myocardial infarction.
Moreover, various papers have revealed that diabetes was closely related to increased incidence of myocardial infarction (22). In our study, the history of Diabetes Mellitus cases were present in 10 patients $(16.6 \%)$ was again supported by various previously reported data.

In the present study it is noted that family history of coronary artery disease is present in 16 patients (26.6\%). In 1984, a study performed by Shea 1984 et al (23) observed that relatives of angiographically demonstrated coronary artery disease had a significantly greater risk for coronary artery disease than control. The present study we estimated total cholesterol (TC), total triglyceride (TG), high density lipoprotein-cholesterol (HDL-C), very low density lipoprotein-cholesterol (VLDL-C) and low density lipoprotein-cholesterol (LDL-C). In the control group, the means of TC, TG, HDL-C, LDL-C and VLDL-C were found to be $172.2 \mathrm{mg} / \mathrm{dl}, 147.6 \mathrm{mg} / \mathrm{dl}$, $45.52,97.16 \mathrm{mg} / \mathrm{dl}$ and $29.52 \mathrm{mg} / \mathrm{dl}$ respectively. In addition, the mean total cholesterol in control group was $177.4 \mathrm{mg} / \mathrm{dl}$ and $156.6 \mathrm{mg} / \mathrm{dl}$ in men and women respectively. Similarly, the mean HDL-C in men and in women was $44.34 \mathrm{mg} / \mathrm{dl}$ and $49.04 \mathrm{mg} /$ $\mathrm{dl}$ respectively. Previous studies have reported that normal female have a lower TC, a higher HDL-C and a lower TC/HDL-C ratio (24). Jan Borgel 2006 et al in (20) demonstrated that females had a lower LDL-C and TC and a higher HDL-C as compared to males. Similar pattern was also reported by Stefan Wieczorek 2007 et al in (25). Among the cases in the present study, the mean TC was $208.53 \mathrm{mg} / \mathrm{dl}$, mean TG was 168.73, mean HDL-C was $41.65 \mathrm{mg} / \mathrm{dl}$, mean LDL-C was $133.13 \mathrm{mg} / \mathrm{dl}$ and mean VLDL-C was 33.74 
$\mathrm{mg} / \mathrm{dl}$. The LDL-C was higher than optimal value showed that levels of these parameters are highly associated in the patients of myocardial infarction as compared to normal population. Similar studies have also been done previously by Nikolaus 2005 et al (26) in 2003; they observed a higher LDL-C and TC as risk factors for the development of myocardial infarction. The mean TC when compared to control showed an increased value. The HDL-C was lower in cases (mean $41.65 \mathrm{mg} / \mathrm{dl}$ ) than control (mean $45.52 \mathrm{mg} / \mathrm{dl}$ ). Low HDL-C was a predictor of CHD. However, Hulley SB 1980 et al (27) showed an inverse relationship between $\mathrm{HDL}-\mathrm{C}$ levels and incidence of myocardial infarction. In the present study the mean TC/HDL-C ratio in cases was 5.154 and that in control was 3.86, so a higher value for the patients of myocardial infarction. In a co-operative lipoprotein phenotyping study showed that a high TC/HDL-C ratio was a predictor of myocardial infarction (28). Nina K. Bartel 2007 et al (19) predicted that a TC/ $\mathrm{HDL}-\mathrm{C}$ ratio greater than 4 was related to the risk of myocardial infarction. Jan Borgel 2006 et al (24) demonstrated that a more than optimal TC/HDL-C ratio was directly related to the risk of myocardial infarction.

\section{Conclusion}

In current study, it has been observed that there is a male predominance as regards myocardial infarction. The patients above the age of 60 years were more prone to develop myocardial infarction and the major risk factors were smoking, hypertension and diabetes. Within 24 hours of myocardial infarction, it has been observed that most of the patients had high level of LDLcholesterol and low level of HDL-cholesterol. None of the patients had high HDL-cholesterol but all patients had high total cholesterol. Hence, inference may be drawn from the present study that the patients who are having low HDL-cholesterol are prone to develop myocardial infarction. This may be an important guideline for preventing cardiac strokes, in future.

\section{References}

1. Miller GJ, Miler NE: plasma HDL concentration and development of ischaemic heart disease: Lancet 1975; 1:9-16.

2. Yokokawa H, Yasumura S, Tanno K et al. Serum low-density lipoprotein to high-density lipoprotein ratio as a predictor of future acute myocardial infarction among men in a. 2.7year cohort study of a Japanese northern rural population. $\mathrm{J}$ Atheroscler Thromb. 2011;18:89-98.
3. Balci B. The modification of serum lipids after acute coronary syndrome and importance in clinical practice. Curr Cardiol Rev. 2011;7(4):272-276.

4. Nigam PK. Biochemical markers of myocardial injury. Indian J Clin Biochem. 2007;22:10-17.

5. Pitt B, Loscalzo J, Ycas J, Raichlen JS. Lipid levels after acute coronary syndromes. J Am Coll Cardiol. 2008;51: 1440-1445.

6. Roubin RS, Barreiro PC, Roubín CF et al. High-sensitivity C-reactive protein predicts adverse outcomes after nonSTsegmentelevation acute coronary syndrome regardless of GRACE risk score, but not after ST-segment elevation myocardial infarction. Rev Port Cardiol. 2013;32:117-122.

7. Swerdlow DI, Holmes MV, Kuchenbaecker KB et al. The interleukin-6 receptor as a target for prevention of coronary heart disease a mendelian randomisation analysis. Lancet. 2012;379:1214-1224.

8. Casas JP, Shah T, Hingorani AD, Danesh J, Pepys MB. C-reactive protein and coronary heart disease: a critical review. J Intern Med. 2008;264:295-314.

9. Bursi F, Weston SA, Killian JM et al. CRP and heart failure after myocardial infarction in the community. Am J Med. 2007;120:616-622.

10. Tarchalski J, Guzik P, Wysocki H. Correlation between the extent of coronary atherosclerosis and lipid profile. . Mol Cell Biochem. 2003;246(1-2):25-30.

11. Gorecki A, Bednarz B, Jaxa-Chamiec T et al. Lipid profile during the first 24 hours after myocardial infarction has significant prognostic value. Kardiol Pol. 2004;60(3): 229236.

12. Ali I, Khan IU, Baloch MK, Mustafa G. Comparative lipid profile studies in cardiac and diabetic conditions. Pak J Pharm Sci. 2004;17(1):25-30.

13. Ferre N, Camps J, Fernandez-Ballart J, et al. Regulation of serum paraoxonase activity by genetic, nutritional, and lifestyle factors in the general population. Clin Chem. 2003;49:1491-1497.

14. Temelkova-Kurktschiev TS, Kurktschiev DP, VladimirovaKitova LG et al. Prevalence and type of dyslipidaemia in a population at risk for cardiovascular death in Bulgaria. Journal of Diabetology. 2009;51(2):22-26.

15. Volmink JA, Newton JN, Hicks NR et al. Coronary event and case fatality rates in an English population: results of the Oxford myocardial infarction incidence study. The Oxford Myocardial Infarction Incidence Study Group. Heart. 1998;80(1):4-40.

16. Tunstall-Pedoe $\mathrm{H}$, Kuulasmaa $\mathrm{K}$, Mähönen $\mathrm{M}$ et al. Contribution of trends in survival and coronary-event rates to changes in coronary heart disease mortality: 10-year results from 37 WHO MONICA project populations. Monitoring trends and determinants in cardiovascular disease. Lancet. 1998;8:1547-1557. 
17. Lerner DJ and Kannel WB. Patterns of coronary heart disease morbidity and mortality in the sexes-A 26 years follow up of Framingham population. Am Heart J. 1986;111:383-390

18. Lampe FC, Whincup PH, Wannamethee SG et al. The natural history of prevalent ischaemic heart disease in middle-aged men. Eur Heart J. 2000;21(13):1052-1062.

19. Nina RV, Gama ME, Santosh AM et al. Is the RACHS-1 (risk adjustment in congenital heart surgery) a useful tool in our scenario. Brito LM.Rev Bras cir Cardiovassc. 2007;4: 425-431.

20. Borgel J, Schulz T, Bartels NK et al. Modifying effects of the R389G beta1-adrenoceptor polymorphism on resting heart rate and blood pressure in patients with obstructive sleep apnoea. Clin Sci (Lond). 2006;110(1):117-123.

21. Bartels NK, Borgel J, Wieczorek S, et al. Risk factors and myocardial infarction in patients with obstructive sleep apnea: impact of beta2-adrenergic receptor polymorphisms. BMC Med. 2007;1:1-5

22. Barrett Connor EL, Cohn BA, Wingard DL, and Edelstei SL. Why is diabetes mellitus a stronger risk factor for fatal ischaemic heart disease in women than in men. The Rancho Burnado study. JAMA. 1991;265:3249.
23. Shea S, Ottman R, Gabrielic et al. Family history- as an important risk factor for coronary heart disease. J Am Coll Cardiol 1984; 4:793-801

24. Mugge A, Hanefeld C, Böger RH. CARDIAC study investigators.. Plasma concentration of asymmetric dimethylarginine and the risk of coronary heart disease: rationale and design of the multicenter CARDIAC study. Atheroscler. 2003;4(4):29-32.

25. Wieczorek S, Arning L, Gizewski ER, Alheite I, Timmann D. Benign SCA14 phenotype in a German patient associated with a missense mutation in exon 3 of the PRKCG gene. Mov Disord. 2007;22(14):2135-2136.

26. Nikolaus S, Larisch R, Wirrwar A et al. Iodobenzamide binding to the rat dopamine $\mathrm{D} 2$ receptor in competition with haloperidol and endogenous dopamine--an in vivo imaging study with a dedicated small animalSPECT. Eur J Nucl Med Mol Imaging. 2005;32(11):1305-1310.

27. Hulley SB, Rosenman RH, Bawol RD, et al. Epidemiology as a guide to clinical decisions. The association between triglyceride and coronary heart disease. $\mathrm{N}$ Engl $\mathrm{J}$ Med. 1980;302:1383-1389.

28. William P, Castelli MD, Joseph T et al. HDL-cholesterol and other lipids in coronary heart disease the co-operative lipoprotein phenotyping study. Circulation. 1977;55: 767-772.

*Corresponding author:

Dr Siddharth Singh, Department of General Medicine AIIMS Patna, Bihar, India-801505

Phone: +91 8986239775

Email: drsiddharthsingh@gmail.com

Financial or other Competing Interests: None. 